+CD3-), T (CD3+CD4+, CD3+CD8+) and NK (CD16/56+CD3-) cells Monocytes were further classified to classical (CD14++CD16-), intermediate $(\mathrm{CD} 14++\mathrm{CD} 16+/++)$ and non-classical $(\mathrm{CD} 14-/+\mathrm{CD} 16++)$ subsets. Data were analysed using Mann Whitney test and expressed as median and interquartile range [IQR].

Results: Out of 49 individuals with arthralgia, 36 were ACPA+ and 28 met CSA definition (15 of them were ACPA+), with symptoms duration 21 months [IQR=53], CRP $3.18 \mathrm{mg} / \mathrm{L}$ [IQR=3.6], DAS28 score 2.28 [IQR=1.31]. As per definition, there was no evidence of clinical arthritis on examination of 66 joints at baseline. Ten individuals developed RA within a median of 4 months of follow up.

Individuals with arthralgia had higher\%CD3+ $\mathrm{T}$ cells $(78.10$ [8.10] vs 75.04 [9.26], $\mathrm{p}=0.001)$ and lower\%NK (11.20 [7.20] vs. 12.89 [6.62], $\mathrm{p} \leq 0.001)$ as well as absolute count of NK cells $(0.18$ [0.13] vs. 0.24 [0.17], $\mathrm{p} \leq 0.001)$ compared to HC. Similarly, higher\%CD3+ T cells $(77.95$ [8.65] vs. 75.04 [9.26], $\mathrm{p}=0.003)$ and lower\%NK (10.85 [7.81] vs. 12.89 [6.62], $\mathrm{p}=0.003)$ and absolute count of NK cells $(0.20$ [0.14] vs. 0.24 [0.17], $\mathrm{p}=0.003$ ) was confirmed in a subgroup of ACPA+ individuals compared to HC. Moreover, individuals who developed RA during follow up, had a lower baseline absolute count of NK cells (0.14 [0.10] vs. 0.19 [0.15], $\mathrm{p}=0.039$ )

Analysis of monocyte subpopulations revealed higher count of non-classical (5.99 [4.87] vs. 4.03; IQR [3.28], $\mathrm{p}=0.022)$ and intermediate (5.82 [2.93] vs. 4.31 [2.08], $\mathrm{p}=0.034$ ) monocytes and lower count of classical monocytes (86.06 [7.69] vs. 89.41 [3.52], $p=0.005)$ in individuals with arthralgia compared to HC. Specifically, also ACPA+ patients had higher count of non-classical (6.07 [5.84 vs. 4.03 [3.28, $\mathrm{p}=0.020$ ) and intermediate (5.86 [3.05] vs. 4.31 [2.08], $\mathrm{p}=0.036$ ) and lower count of classical (85.43 [8.34] vs. 89.41 [3.59], $\mathrm{p}=0.005$ ) monocytes compared to $\mathrm{HC}$. There was no difference in\% or absolute count of lymphocytes and monocytes subpopulations at the time of manifestation of RA and between ACPA+ and ACPA- individuals.

Conclusion: We show lower numbers of NK cells and classical monocytes and expansion of intermediate and non-classical monocytes in individuals in the preclinical phase of RA, especially in ACPA+ individuals Such disproportion or pro-inflammatory potential of these cells was previously shown in the pathogenesis of established RA. We hypothesize that the dysregulation observed in at-risk individuals may be a prognostic marker and a predisposition leading to further development of RA. Acknowledgement: Projects AZV-17-32612A and MHCR 023728

Disclosure of Interests: Klára Prajzlerová: None declared, Olga Kryštfková: None declared, Petra Hánová: None declared, Hana Hulejova: None declared, Monika Gregová: None declared, Karel Pavelka: None declared, Jiř́ Vencovský Consultant for: Samsung, Speakers bureau: AbbVie, Novartis, Pfizer, Sanofi, Eli Lilly, Biogen, UCB, MSD, Werfen, Roche, Ladislav Šenolt Grant/research support from: AbbVie, Consultant for: AbbVie, Bristol-Myers Squibb, Celgene Corporation, Merck Sharp and Dohme, Novartis, Pfizer, Roche, UCB, Amgen, Takeda, Speakers bureau: AbbVie, Amgen, Bristol-Myers Squibb, Celgene Corporation, Eli Lilly, Merck Sharp and Dohme, Novartis, Pfizer, Roche, UCB, Mária Filková: None declared DOI: 10.1136/annrheumdis-2019-eular.6686

\section{THU0063 PRE-MRNA SPLICING ALTERATIONS IN FOLYLPOLYGLUTAMATE SYNTHETASE IN BLOOD CELLS OF EARLY RHEUMATOID ARTHRITIS PATIENTS ARE ASSOCIATED WITH UNRESPONSIVENESS TO METHOTREXATE}

Ittai Muller ${ }^{1}$, Marry Lin ${ }^{1}$, Willem Lems ${ }^{2}$, Marieke Ter Wee ${ }^{2,3}$, Jacqueline Cloos ${ }^{4}$ Yehuda Assaraf ${ }^{5}$, Gerrit Jansen ${ }^{2}$, Robert De Jonge ${ }^{1} .{ }^{1}$ Amsterdam UMC, Vrije Universiteit Amsterdam, Department of Clinical Chemistry, Amsterdam, Netherlands: ${ }^{2}$ Amsterdam UMC, Vrije Universiteit Amsterdam, Department of Rheumatology, Amsterdam Infection and Immunity Institute, Amsterdam, Netherlands; ${ }^{3}$ Amsterdam UMC, Vrije Universiteit Amsterdam, Department of Epidemiology and Biostatistics, Amsterdam, Netherlands; ${ }^{4}$ Amsterdam UMC, Vrije Universiteit Amsterdam, Department of Hematology, Amsterdam, Netherlands ${ }^{5}$ Technion-Israel Institute of Technology, Department of Biology, Haifa, Israel

Background: Low-dose methotrexate (MTX) serves as the first-line treatment for rheumatoid arthritis (RA). Conversely, for hematological malignancies, high-dose MTX treatment is indicated in combination with folinic acid/leucovorin to prevent untoward toxicity. For both disease modalities, efficient pharmacological response critically depends on the retention and accumulation of intracellular MTX. The latter process is mediated by the enzyme folylpolyglutamate synthetase (FPGS) through MTX conversion into MTX-polyglutamates (MTX-PG). As such, decreased FPGS activity has been recognized as a mode of MTX resistance, but the underlying molecular mechanism has not yet been pinpointed [1,2]. Recently, aberrant pre-mRNA splicing of FPGS in acute lymphoblastic leukemia cells was associated with reduced FPGS activity, decreased MTX-PG accumulation and lower overall survival. Specifically, a partial retention of FPGS intron 8 (8PR) was identified as a prominent splice variant causing FPGS dysfunction [3]

Objectives: To investigate whether the expression of the FPGS premRNA variant partial retention of intron 8 is associated with MTX unresponsiveness in RA patients over 3-6 months of MTX therapy.

Methods: Patients were enrolled from the COBRA-light trial comprising MTX treatment [4]. After informed consent, blood was obtained from 38 patients in either the COBRA $(n=15)$ or the COBRA-light $(n=21)$ treatment arm [4] and collected in Paxgene tubes for RNA isolation. Two patients were excluded due to insufficient sample quality. Quantitative PCR techniques were used to assess the ratios of FPGS 8PR over wild type FPGS (8WT) expression in whole blood RNA. Remission was defined as a DAS44 < 1.6

Results: Baseline ratios of $8 \mathrm{PR} / 8 \mathrm{WT}$ were associated with a decline in DAS44 at T3 $(p=0.001)$ and T6 $(p=0.13)$ in the COBRA-light patients. T3 ratios were also associated with DAS44 at T6 $(p=0.001)$ and $\triangle \mathrm{DAS} 44$ at T6 $(p=0.26)$. Logistic regression analysis showed that in COBRA-light patients baseline ratios of $8 P R / 8 W T$ were associated $(p=0.05)$ with the probability of T3 remission but not T6 remission. T3 ratios of 8PR/8WT in COBRA-light patients were similarly associated with T6 remission but not with T3 remission. COBRA patients also showed a significant association between baseline 8PR/8WT ratios and DAS44 at T6 $(\mathrm{p}=0.04)$ while T3 ratios of $8 \mathrm{WT} / 8 \mathrm{PR}$ were significantly associated with DAS44 at T3 $(\mathrm{p}=0.03)$ and T6 $(\mathrm{p}=0.05)$. However, analysis of COBRA patients showed no significant associations between baseline 8PR/8WT ratios and T3/T6 remission, nor associations between $\mathrm{T} 3$ ratios and T3/T6 remission.

Conclusion: These results demonstrate that a higher expression of an intron 8 retention of FPGS mRNA is associated with a higher DAS44 at T3 and T6 in COBRA-light patients, and at T6 for COBRA patients Moreover, in COBRA-light patients, baseline expression of 8WT/8PR is significantly associated with remission at T3 or T6. This study is the first to show the impact of FPGS pre-mRNA splicing alterations in relation to unresponsiveness to MTX treatment in RA.

\section{REFERENCE:}

[1] PM Brown et al, Nat Rev Rheumatol. 2016;12:731-742. [2] S Raz et al, Drug Resist Updat. 2016;28:43-64. [3] A Wojtuszkiewicz et al, Haematologica. 2016;101:e291-294. [4] D den Uyl et al, Ann Rheum Dis $2014 ; 73: 1071-1078$

Disclosure of Interests: Ittai Muller: None declared, Marry Lin: None declared, Willem Lems Speakers bureau: Amgen Inc., Merck, Eli Lilly and Pfizer, Marieke ter Wee Grant/research support from: Nonrestricted grant from Lilly Netherlands BV, Speakers bureau: ARC Preceptorship program, Jacqueline Cloos: None declared, Yehuda Assaraf: None declared, Gerrit Jansen: None declared, Robert De Jonge: None declared DOI: 10.1136/annrheumdis-2019-eular.3215

\section{THU0064 COMPARISON OF MORTALITY IN RHEUMATOID ARTHRITIS AND DIABETES - THE HUNT POPULATION- BASED STUDY}

Ingrid Saether Houge ${ }^{1}$, Mari Hoff ${ }^{1}, 2$, Ranjeny Thomas ${ }^{3}$, Vibeke Videm ${ }^{1,2} .{ }^{1} N T N U$ Norwegian University of Science and Technology, Trondheim, Norway; ${ }^{2}$ St. Olavs University Hospital, Trondheim, Norway, ${ }^{3}$ University of Queensland, Brisbane, Australia

Background: Patients with rheumatoid arthritis (RA) have higher mortality rates than the general population, primarily from cardiovascular disease (CVD). Diabetes is an acknowledged risk factor for early death, mainly due to CVD. The reported risk for CVD is increased for both patients with RA and diabetes, however the effect of diabetes appears to be greater than that of RA (1)

Objectives: To assess whether the increase in all-cause mortality rates in patients with RA and patients with diabetes are similar, compared to the general population.

Methods: Data were obtained from the $2^{\text {nd }}$ and $3^{\text {rd }}$ survey of the population-based Nord Trøndelag Health Study (HUNT) and the Norwegian National Cause of Death Registry. The RA diagnoses have previously been validated (2). The definition of diabetes was self-reported diabetes, self-reported use of antidiabetica, or non-fasting blood glucose level $>11.1$ $\mathrm{mmol} / \mathrm{L}$. The participants were followed from their participation in HUNT to death or to 31.12.2014, whichever came first. Participants with other types of inflammatory arthritis or missing data for any of the variables in 